\title{
Expression of Histocompatibility 2 Blastocyst (H2-Bl) in Embryonic Stem Cells Inhibits CD8+ T-Cell Activation but is not Sufficient to Facilitate Graft Tolerance
}

\author{
Steven Dingwall ${ }^{1,2}$, Andrew Brooks ${ }^{3,4}$, Simon H Apte ${ }^{5}$, Mike Waters ${ }^{6}$, Martin F Lavin ${ }^{2}$ and Ernst J Wolvetang ${ }^{1 *}$ \\ ${ }^{1}$ Australian Institute for Bioengineering and Nanotechnology, University of Queensland, Brisbane, 4072, Australia \\ ${ }^{2}$ The University of Queensland Centre for Clinical Research, University of Queensland, Brisbane, Queensland, 4029, Australia \\ ${ }^{3}$ Institute of Molecular Bioscience, University of Queensland, Brisbane, 4072, Australia \\ ${ }^{4}$ The University of Queensland Diamantina Institute, The University of Queensland, Translational Research Institute, QId 4072, Australia \\ ${ }^{5}$ Queensland Institute for Medical Research Berghofer, Brisbane, 4006, Australia \\ ${ }^{6}$ Diamantina Institute, University of Queensland, Brisbane, 4072, Australia
}

\begin{abstract}
Universal embryonic stem cell donor lines would greatly facilitate stem cell based regenerative medicine and permit facile testing of human pluripotent stem cell derived grafts in xenogeneic settings. Because HLA-G overcomes immune cell mediated attack of foetal tissues during pregnancy and inhibits T-cell responses and dendritic cell antigen maturation in vitro and in vivo, it is an attractive candidate molecule for achieving this goal. Here we investigated whether enforced expression of either the soluble or the membrane bound form of the HLA-G mouse homologue, H2$\mathrm{Bl}$, in human and mouse ES cell lines would allow engraftment in immunocompetent mice. Despite evidence for robust expression of soluble or membrane bound $\mathrm{H} 2-\mathrm{BI}$ molecules and effective inhibition of CD8+ T-cell proliferation by all $\mathrm{H} 2-\mathrm{BI}$ engineered ES cell lines, all failed to generate teratomas in immunocompetent mice, despite doing so in NODSCID mice. We conclude that expression of $\mathrm{H} 2-\mathrm{BI}$ in human and mouse embryonic stem cells alone is insufficient to overcome xenogeneic rejection.
\end{abstract}

Keywords: Human embryonic stem cells; Mouse embryonic stem cells; HLA-G; H2-Bl; Immune tolerance

\section{Introduction}

Several barriers to the utilization of pluripotent stem cell derived products in the treatment of disease still exist. One such barrier is the potential for immune rejection of embryonic stem cell (ESC) derived tissues and cells after transplantation. Work with mouse embryonic stem cells (mESCs) proposed that low expression of major histocompatibility complex (MHC) class I, MHC class II and non-classical antigens [1] as well as inhibition of T-cell maturation by transforming growth factor $\beta$ [2] may result in immunological tolerance of these cells in transplantation settings. However, it was observed that while MHC class I molecules were expressed at very low levels in undifferentiated human embryonic stem cells (hESCs), there is an increase in expression upon differentiation and a dramatic elevation in response to IFN-gamma which is secreted by multiple types of immune cells [3]. Evidently, additional strategies to avoid immunogenic rejection of embryonic stem cell derived products must be developed. There are four broad approaches that are currently being attempted; producing banks of HLA-matched pluripotent cells, immune suppression of recipients, production of gene corrected iPS cells, and alteration of the intrinsic immunogenicity of the donor cells.

Major histocompatibility complexes (human leukocyte antigen (HLA) in humans), which normally act to present antigens to cells of the immune system, can themselves be recognized as antigens and induce an immune response [4]. MHC molecules fall into three broad classes (denoted MHC class I, II, and III). Amongst these MHC class I molecules (which include HLA-A, B, C, E, F, G in humans) were found to be the primary causative agents in the induction of an immune response following hESC transplantation [5]. For organ transplantation, matching of HLA antigens is often used and has been shown to be a good indicator of graft acceptance.

It has been proposed that producing a bank of iPSCs from selected HLA-typed volunteers may similarly avoid immune rejection and facilitate transplantation. It was calculated that a bank of 150 iPSC cell lines could provide matched stem cells for $93 \%$ of the U.K. population [6]. While these predictions are encouraging, it remains to be determined how effective HLA matching will be for successful transplantation and long term engraftment, given that even minor histocompatibility complexes $(\mathrm{mH})$, peptides carrying unique polymorphisms, appear to be sufficient to induce acute rejection of mESCs upon allogenic transplantation [7].

Another option, also employed in organ transplantation, is the suppression of the immune response. Experiments with the clinically available immunosuppressant drugs Sirolimus, mycophenolate mofetil, and Tacrolimus were only able to partially mitigate the immune response following injection of hESCs into an immune competent mouse, and these xenogenic grafts were rejected within 28 days [8]. Continuous treatment with cyclosporine $\mathrm{A}$ on the other hand does permit persistence and long-term engraftment of human ES and iPSC derived cell types in immuno-competent recipients [9-13]. However, such continuous immune suppression would leave a recipient vulnerable to opportunistic infection, and is therefore not a favourable

*Corresponding author: Professor Ernst Wolvetang, Ph.D, Group leader, Stem Cell Engineering Group, Australian Institute for Bioengineering and Nanotechnology, Level 4, Building 75, University of Queensland, St Lucia, QLD, Australia, 4072, Tel: 61-7-33463894, 0466655 536; E-mail: e.wolvetang@uq.edu.au

Received November 11, 2015; Accepted December 11, 2015; Published December 13, 2015

Citation: Dingwall S, Brooks A, Apte SH, Waters M, Lavin MF, et al. (2015) Expression of Histocompatibility 2 Blastocyst $(\mathrm{H} 2-\mathrm{BI})$ in Embryonic Stem Cells Inhibits CD8+ T-Cell Activation but is not Sufficient to Facilitate Graft Tolerance. Stem Cell Res Ther 5: 320. doi:10.4172/2157-7633.1000320

Copyright: (c) 2015 Dingwall S, et al. This is an open-access article distributed under the terms of the Creative Commons Attribution License, which permits unrestricted use, distribution, and reproduction in any medium, provided the original author and source are credited. 
Citation: Dingwall S, Brooks A, Apte SH, Waters M, Lavin MF, et al. (2015) Expression of Histocompatibility 2 Blastocyst (H2-BI) in Embryonic Stem Cells Inhibits CD8+ T-Cell Activation but is not Sufficient to Facilitate Graft Tolerance. J Stem Cell Res Ther 5: 320. doi:10.4172/21577633.1000320

Page 2 of 8

approach. Alternative immune suppression strategies for pluripotent stem cell based therapies, using a leukocyte co-stimulatory blockade [14], have meanwhile been developed. While administration of costimulatory blocking agents (anti-CD40L, anti-LFA and CTLA-4-Ig) during the first 6 days following injection facilitated engraftment of pluripotent (mESC, hESC, miPSC, hiPSC) as well as mouse bone marrow mononuclear cells for up to $\sim 50-70$ days post injection, it remains to be determined how this approach affects the long term immune competence of the recipient mice. Similar to traditional immune suppression, these treatments may leave patients vulnerable to opportunistic infection.

An attractive solution for the evasion of immunogenicity of stem cell transplantation is to produce patient specific induced pluripotent stem cells (iPSCs). While early reports questioned the immunogenicity of iPSC [15], this was subsequently refuted [16], and next shown to be dependent on the specific cell type that is delivered [17]. While it is not unlikely that iPSCs will ultimately provide a source of tissues and cells for autologous transplantation, enabling such iPSC-based cellular therapies will require cheap plug-and-play type generation of iPSCs under xeno-free GMP compliant conditions in hospital settings and will require rapidly obtainable, robust safety criteria.

It is clear that human pluripotent stem cell based therapies would greatly benefit from the production of a thoroughly characterised "universal donor ES-cell" that can be accepted by the immune system of any patient. The production of such a cell line was pioneered by Deusse et al by knocking down HLA class I in hESCs [5]. While these cells certainly proved to be less immunogenic than their wild type counterpart, approximately $50 \%$ of grafts were still rejected from immune competent mice.

Here we have attempted to take advantage of the mouse homologue of the immunotolerogenic molecule HLA-G (known as $\mathrm{H} 2-\mathrm{Bl}$ ) to produce pluripotent cell lines compatible with allogenic and possibly xenogenic transplantation. Our decision to test this molecule was based on its expression on the maternal foetal interface of trophoblast cells [18], where it plays a key role in maternal immunotolerance of the foetus, and protects trophoblasts from maternal natural killer (NK) cell lysis [19]. It was further shown that this protection was transferable to other cells, as cytotrophoblasts transfected with either HLA-G1 or HLA-G2 cDNA, were also protected from NK cell induced cell lysis [20]. As graft rejection is for a large part mediated by host $\mathrm{T}$-cells recognizing polymorphisms in MHCs and mHs [21], a role for HLA-G in T-cell mediated immune suppression was inferred. Indeed, HLA-G inhibits CD8+ cytotoxic T lymphocytes (CTL) [22], CD4+ T-Cell proliferation [23], and can induce immunosuppressive CD4+ T regulatory cells [24]. Furthermore, HLA-G also inhibits the maturation of antigen presenting dendritic cells [25]. The role of HLA-G in mediating immune tolerance further extends well beyond pregnancy. Detection of soluble HLA-G in patients receiving heart [26], liver [27], or kidney [28], transplants is associated with enhanced graft acceptance and human muscle cell lines transiently transfected with HLA-G1 and HLA-G5 expression constructs elicit reduced human cytotoxic T-cells responses and undergo less NK cell induced lysis [29]. Based on the ability of HLA-G to inhibit multiple mechanisms associated with immune rejection, we were interested to find out whether expression of different $\mathrm{H} 2-\mathrm{Bl}$ isoforms could facilitate transplantation of human and mouse ES-cells in immune competent mice.

\section{Materials and Methods}

\section{hESC cell culture conditions}

hESCs were cultured in knock out serum (KSR) replacement hESC culture medium (80\% DMEM F12 (GIBCO), 20\% KnockOut-Serum replacement (GIBCO), $2 \mathrm{mM}$ L-glutamine (GIBCO), $1 \%$ non-essential amino acids (NEAA) (GIBCO), $0.1 \mathrm{mM} \mathrm{2-mercaptoethanol} \mathrm{100ng/}$ $\mathrm{ml}$ basic fibroblast growth factor) (Invitrogen) at $37^{\circ} \mathrm{C}$ at $5 \% \mathrm{CO}_{2}$ and at high humidity. Cells were cultured in feeder-free conditions on Matrigel $^{\mathrm{TM}}$ (BD) in MEF conditioned hESC culture medium. Cells were passaged with collagenase IV $(1 \mathrm{mg} / \mathrm{ml})$ (Stem Cell Technologies) before replating at a seeding ratio of between 1:2 and 1:6. hESC media was replaced daily and cells were split at approximately $80 \%$ confluence on days 6-7.

\section{mESC culture conditions}

mESCs were grown in knock out serum (KSR) replacement ESC culture medium (80\% DMEM F12 (GIBCO), 20\% KnockOut-Serum replacement (GIBCO), $2 \mathrm{mM}$ L-glutamine (GIBCO), $1 \%$ non-essential amino acids (NEAA) (GIBCO), $0.1 \mathrm{mM}$ 2-mercaptoethanol $1000 \mathrm{U} /$ $\mathrm{ml}$ murine leukemia inhibitory factor (mLIF) (Invitrogen) at $37^{\circ} \mathrm{C}$ at $5 \% \mathrm{CO}_{2}$ and at high humidity. Cells were maintained on mouse embryonic fibroblasts (MEFs) at a density of $0.8 \times 10^{5} \mathrm{cells} / \mathrm{cm}^{2}$. For experimentation, cells were cultured in feeder-free conditions on Matrigel $^{\mathrm{TM}}(\mathrm{BD})$ in MEF conditioned ESC culture medium. Cells were passaged using trypsin to dissociate cells into small clumps before replating at a seeding ratio of between 1:2 and 1:6. ESC media was replaced daily and cells were split at approximately $70 \%$ confluence on days 2-3.

\section{Generation of $\mathrm{H} 2-\mathrm{Bl}$ expressing cells}

pLenti plasmids containing one of the $\mathrm{H} 2-\mathrm{Bl}$ isoforms (a soluble form from C57BL/6 mice and a membrane bound form from 129/ SvJ) or a GFP control were produced using the Gateway ${ }^{\circledR}$ cloning system. An HA tag sequence was introduced in the 3' Primer to encode the HA tage at the C-terminus. 293FT cells were transfected with the lentiviral vector DNA, PMDg, PRSV-Rev, and pVSVg using Lipofectamine 2000 (all from Invitrogen) and virus was collected 36 hours post-transfection. This virus was then used to transduce desired cells for 24 hours in presence of $7 \mu \mathrm{g} / \mathrm{ml}$ polybrene (Sigma). Feeder free cultured Cells were expanded for 5 days after which they were selected using $2 \mu \mathrm{g} / \mathrm{ml}$ puromycin. Resistant colonies were picked after 4 days, expanded and cryopreserved.

\section{Western blotting}

Cells were washed twice with $1 \times \mathrm{PBS}$ and then lysed with $5 \times$ loading buffer (130 mM Tris pH 6.8, 4\% SDS, 0.02\% Bromophenol blue, 20\% glycerol, $100 \mathrm{mM}$ DTT) containing 10\% PhosSTOP phosphatase inhibitor (Roche). They were subsequently homogenized using $30 \mathrm{G}$ needles and heated to $80^{\circ} \mathrm{C}$ for 10 mins. Proteins were resolved using sodium dodecyl sulphate polyacrylamide gel electrophoresis (SDS-PAGE). The iBlot ${ }^{\circledR}$ Dry Blotting System (Invitrogen) was used to transfer proteins to a PVDF membrane. Blots were submerged in blocking buffer (Tris-buffered saline with $0.01 \%$ Tween-20 (TBST) and $5 \%$ Bovine serum albumin $(\mathrm{BSA}))$ at room temperature $\left(\sim 21^{\circ} \mathrm{C}\right)$ for 2 hours. Blots were then then probed with appropriate antibodies diluted in blocking buffer at $4^{\circ} \mathrm{C}$ over-night with gentle agitation. Probes were then washed three times for 15 minutes each, before submersion in appropriate secondary antibodies diluted in blocking buffer for one hour at room temperature. Blots were thenwashed as before and analysed using Pierce ECL Western Blotting detection kit according to manufacturer's recommendation (Thermo Scientific) on the V3- 
Citation: Dingwall S, Brooks A, Apte SH, Waters M, Lavin MF, et al. (2015) Expression of Histocompatibility 2 Blastocyst (H2-BI) in Embryonic Stem Cells Inhibits CD8+ T-Cell Activation but is not Sufficient to Facilitate Graft Tolerance. J Stem Cell Res Ther 5: 320. doi:10.4172/21577633.1000320

Page 3 of 8

Western Workflow (Bio-Rad) for a densitometric representation. The images were respectively analyzed using either One-Rad (Bio-Rad) or Image Lab (Bio-Rad).

\section{Immunostaining}

For immunostaining cells were washed in PBS and fixed in $4 \%$ paraformaldehyde for 15 minutes at $4^{\circ} \mathrm{C}$. For nuclear staining samples were permeabilized in $0.1 \%$ Triton X-100 at room temperature for 10 minutes, before blocking with $10 \%$ goat serum and incubation with the relevant antibodies overnight at $4^{\circ} \mathrm{C}$. Antibodies and dilutions used were OCT4 (Millipore) [1:1000], NANOG (Millipore) [1:400], and HA (Cell Signalling) [1:1000]. Following washing with PBS (3 times for 5 $\mathrm{min}$ at room temperature) secondary antibodies goat anti-mouse $\mathrm{IgG}_{1}$, goat anti-mouse $\operatorname{IgG}_{2 \mathrm{~B}}$, goat anti-mouse IgM and Donkey anti-rabbit IgG (Alexa fluor) [1:1000] were used. Nuclei were stained with DAPI. This preparation minus the addition of primary antibody was used to confirm specificity of staining.

\section{In vivo $\mathrm{T}$ cell activation assay}

1 million ESCs were delivered via tail vein injection into into NOD. Rag1-/-.IL-2ryc-/- (NRG) mice (Jax Laboratories). 24 hours following injections of ESCs 5 million splenocytes which had been incubated for $10 \mathrm{~min}$ in $1 \mu \mathrm{M}$ violet proliferation dye 450 (VPD450) (Thermo Scientific) were injected per animal. At day 7, splenocytes were harvested for flow cytometry.

For flow cytometry, cells were incubated on ice with conjugated anti-CD8 antibodies with $1 \mathrm{mg} / \mathrm{ml}$ propidium iodide (Calbiochem, San Diego, CA). Flow cytometric analysis was performed on a LSR Fortessa (BD Biosciences, North Ryde, NSW, Australia) with standard optics configuration (405 $\mathrm{nm}$ violet laser, $488 \mathrm{~nm}$ blue laser, $633 \mathrm{~nm}$ red laser) with CellQuest version 3.1F software (BD Biosciences, San Jose, CA). Post-acquisition data analysis was performed with FlowJo software (Treestar, Ashland, OR, USA).

\section{Teratoma formation}

hESCs collected by collagenase IV treatment and mESCs were collected by trypsin treatment. One million cells, resuspended in 50 $\mu \mathrm{L}$ DMEM/F12 supplemented with 50\% BD Matrigel ${ }^{\mathrm{TM}}$, were injected into hind limb muscles of Methoxyflurane anaesthetised 6-week-old SCID or CB7BL/6 mice (from the Animal Resource Centre (ARC) in Western Australia). After eight to ten weeks, teratomas were dissected and fixed in $4 \%$ paraformaldehyde. Samples were embedded in paraffin, stained with haematoxylin and eosin and examined for the presence of representatives of the three germlayers. All mouse procedures were conducted under local ethical guidelines and after gaining permission from the local animal ethics committee (University of Queensland, QLD, Australia).

\section{Statistics}

Data represent mean \pm S.D of the number $(n)$ of independent experiments unless indicated otherwise. Statistical significance has been calculated by a two-way ANOVA with Bonferroni post-tests to compare replicate means between the indicated groups for all experiments or via student's T-test where appropriate.

\section{Results}

The human HLA-G gene and its mouse homologue $\mathrm{H} 2-\mathrm{Bl}$ are composed of 8 exons which can be alternatively spliced to produce several different isoforms. Exon 1 codes for the leader fragment, exon 2, 3, and 4 encode the 3 extracellular domains ( $\alpha 1, \alpha 2$, and $\alpha 3$ respectively), exon 5 encodes the transmembrane domain and exon 6 encodes the cytoplasmic tail. Exon 7 is not transcribed and exon 8 is the 3' UTR region [30]. Seven different isoforms of human HLA-G are currently known and the mouse homolog $(\mathrm{H} 2-\mathrm{Bl})$ can be alternatively spliced into at least 3 different isoforms [31,32]. Here we have used the mouse isoforms most similar to human HLA-G1 (referred to as Membrane Bound (M)) and most similar to human HLA-G5 (referred
A
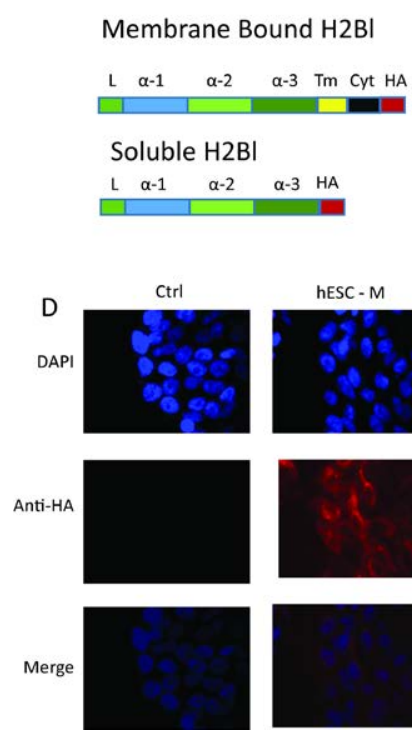
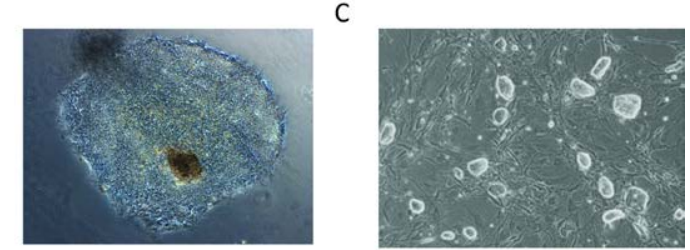

$\mathrm{E}$
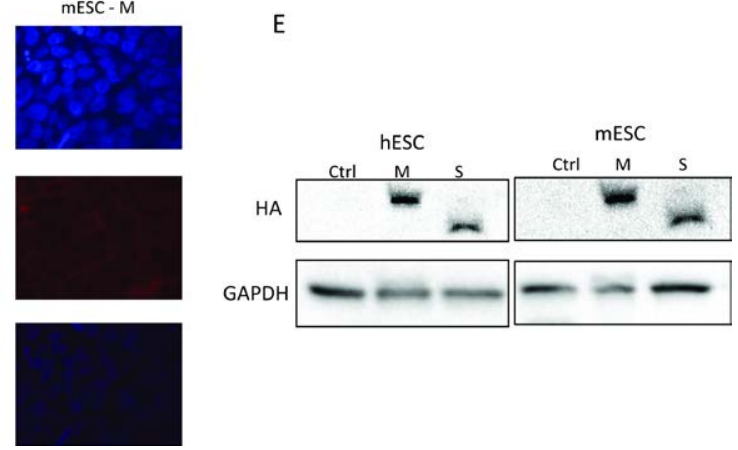
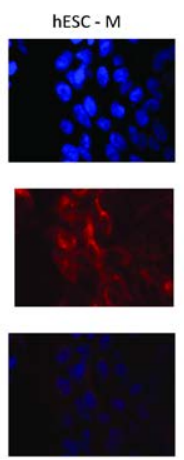

Figure 1: Generation of H2-BI Expressing mESC and hESC Cell lines. (A) Schematic representation of the membrane bound (MB) and soluble (S) isoforms of H2-B used in these experiments. (B) Phase contrast image of the hESC line ENVY. (C) Phase contrast image of the mESC line R1. (D) The HA tag on of membrane bound $\mathrm{H} 2-\mathrm{BI}$ molecule was detectable in both ES cell lines as shown by immunofluorescence. (E) Presence of both isoforms of the H2-BI protein as detected by western blotting. 
Citation: Dingwall S, Brooks A, Apte SH, Waters M, Lavin MF, et al. (2015) Expression of Histocompatibility 2 Blastocyst (H2-BI) in Embryonic Stem Cells Inhibits CD8+ T-Cell Activation but is not Sufficient to Facilitate Graft Tolerance. J Stem Cell Res Ther 5: 320. doi:10.4172/21577633.1000320

Page 4 of 8

to as Soluble (S)) (Figure 1A). The human ESC line ENVY (Figure $1 \mathrm{~B})$, previously shown to constitutively express high levels of GFP throughout differentiation [33], and the mouse ESC line R1 (Figure 1C) were stably transduced with lentivirus encoding either the membrane bound (MB) or soluble (S) form of the mouse $\mathrm{H} 2-\mathrm{Bl}$ protein, driven by the PGK reporter, and containing a puromycin resistance gene cassette. The $\mathrm{H} 2-\mathrm{Bl}$ sequences were modified to include a C-terminal HA tag allowing for identification of the protein, as no antibody currently exists for $\mathrm{H} 2-\mathrm{Bl}$. The HA tag of membrane bound protein was detectable by immunofluorescence (Figure 1D) and both forms were detectable by western blot analysis (Figure 1E) in both hESC and mESC, indicating that transduction successfully produced mESC and hESC that constitutively express the membrane bound or soluble form of the $\mathrm{H} 2-\mathrm{Bl}$ protein.

The transduced murine and human ES cell lines maintained their pluripotency following puromycin selection as indicated by robust staining for the nuclear markers of pluripotency Nanog (Figure 2A) and Oct4 (Figures 2B and 2C).

To verify that the soluble $\mathrm{H} 2-\mathrm{Bl}(\mathrm{S}-\mathrm{H} 2 \mathrm{Bl})$ and membrane bound $\mathrm{H} 2-\mathrm{Bl}(\mathrm{M}-\mathrm{H} 2 \mathrm{Bl})$ expressing human and mouse cell lines were truly pluripotent we next performed teratoma assays in nonobese diabetic/ severe combined immunodeficiency (NOD/SCID) mice. Following intramuscular injection into immune compromised NOD/SCID mice, all hESC and mESC cell lines formed teratomas containing tissues of all three germ layers (endoderm, mesoderm, and ectoderm) (Figure 3 and Supplemental Figure 1).

We next performed G-band karyotype analyses on the parental

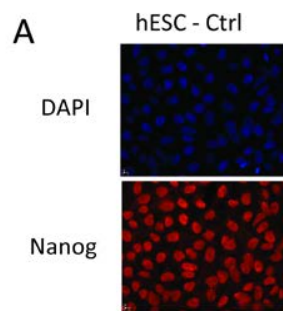

B

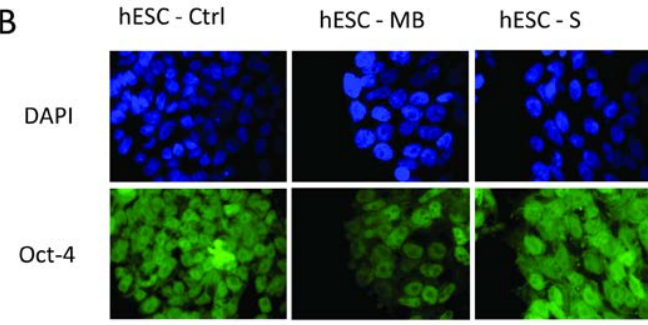

C

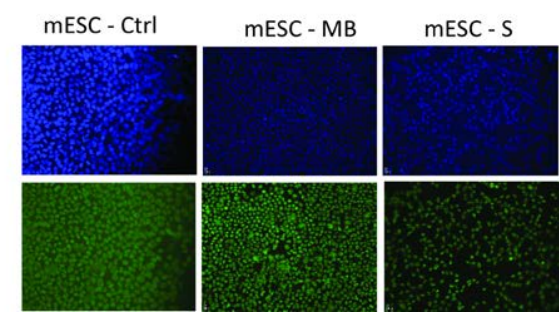

Figure 2: $\mathrm{H} 2-\mathrm{BI}$ transduced $\mathrm{mES}$ and hESC express pluripotency markers. (A) All transduced hESC lines exhibit expression of the nuclear pluripotency marker Nanog. The nuclear pluripotency marker Oct-4 was also detected in transduced mouse $(B)$ and human $(C)$ ESC lines.

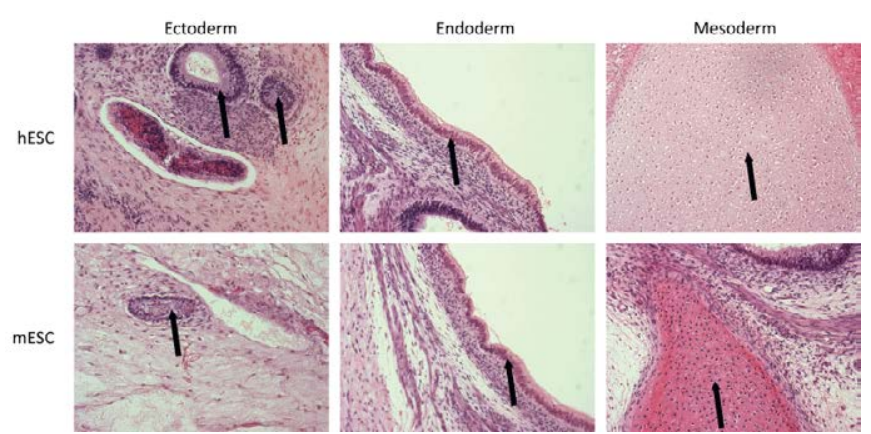

Figure 3: $\mathrm{H} 2-\mathrm{BI}$ transduced $\mathrm{mES}$ and hESC form teratomas in NOD-SCID mice. H\&E stained images of paraffin embedded teratomas from parental lines show the presence of tissues from all three germ layers.

cell lines (Supplemental Figure 2) and discovered that transduced ENVY hESC cells exhibited a normal karyotype with the exception of a missing X chromosome 45, X-X. As this karyotype was consistent across all cells analysed, and did not alter the expression of HLA or the capacity to differentiate into all three germ layers, it was concluded that the loss of the chromosome in these cells would not interfere with our ability to assess the effect of $\mathrm{H} 2-\mathrm{Bl}$ expression on immune mediated cell rejection.

We next assessed whether M-H2BL and S-H2Bl expression altered the proliferation or survival of hESCs and mESCs, as this could affect the capacity of the cells to proliferate in an in vivo environment and therefore the immunogenicity of the cells. We detected no significant difference in either the growth rate (Figures $4 \mathrm{~A}$ and $4 \mathrm{~B}$ ) or viability (Figures 4C and 4D) between any of the transduced hESCs and mESCs relative to each other or their parental cell lines.

Previous studies have found $\mathrm{CD}^{+} \mathrm{T}$-cells to play a major role in the rejection of pluripotent stem cell derived cells and tissues [8,14,34]. As such, we chose to assess the capacity of the $\mathrm{H} 2-\mathrm{Bl}$ molecule to inhibit ES cell induced $\mathrm{CD}^{+} \mathrm{T}$-cell proliferation in an in vivo situation. Parental as well as $\mathrm{S}-\mathrm{H} 2 \mathrm{Bl}$ and $\mathrm{M}-\mathrm{H} 2 \mathrm{Bl}$ transduced ESC lines were injected via tail vein into NOD.Rag1-/-.IL-2ryc-/- (NRG) mice. 24 hours following injections MACS bead sorted $\mathrm{CD}^{+}$cells (isolated from the spleen of $\mathrm{BALB} / \mathrm{c}$ mice) were stained with violet proliferation dye 450 (VPD450) and injected via tail vein injection (Figure $5 \mathrm{~A}$ ). The number of $\mathrm{CD} 8^{+}$ $\mathrm{T}$ cell divisions were next assessed at day 7 following ESC injections (Figure 5B). The median fluorescence intensity of the VDP450-labelled $\mathrm{T}$ cells was significantly lower in mice that received untransduced hESCs when compared to mice that received hESCs transduced with either S-H2Bl or MB-H2Bl (Figure 5C); we also observed a significant increase in the percentage of cells which had undergone $\geq 1, \geq 2$, or $\geq 3$ cellular divisions (Figures $5 \mathrm{D}-5 \mathrm{~F}$ ) in mice receiving the parental controls, indicating that both $\mathrm{H} 2-\mathrm{Bl}$ isoforms are capable of inhibiting $\mathrm{CD}^{+} \mathrm{T}$-cell proliferation.

To test whether $\mathrm{M}-\mathrm{H} 2 \mathrm{Bl}$ and/or S-H2BL expression was sufficient to evade the immune response of immune competent animals, all human and mouse ESC lines were injected intramuscularly into both NOD/SCID and C57BL/6 mice. While all of the cell lines were capable of forming at least one teratoma in the NOD/SCID recipients, no teratomas were observed when any of the cell lines were injected into wild type C57BL/6 mice (Figure 6), indicating that $\mathrm{H} 2-\mathrm{Bl}$ expression did not facilitate transplantation into immune competent animals. To assess whether this was perhaps related to insufficient expression levels 
Citation: Dingwall S, Brooks A, Apte SH, Waters M, Lavin MF, et al. (2015) Expression of Histocompatibility 2 Blastocyst (H2-BI) in Embryonic Stem Cells Inhibits CD8+ T-Cell Activation but is not Sufficient to Facilitate Graft Tolerance. J Stem Cell Res Ther 5: 320. doi:10.4172/21577633.1000320

A

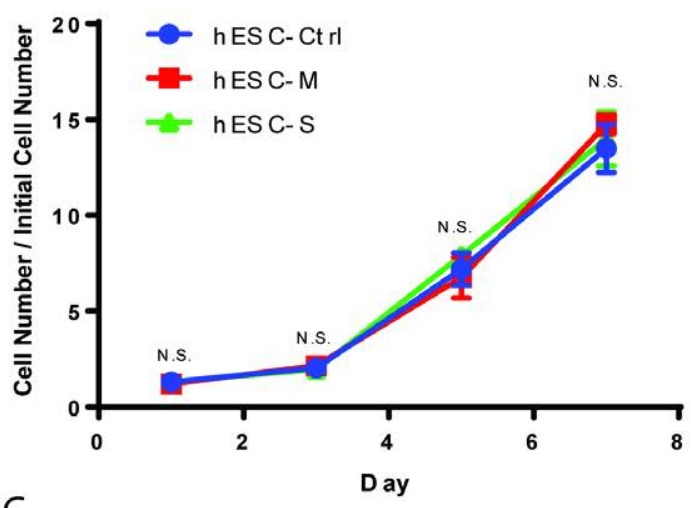

C

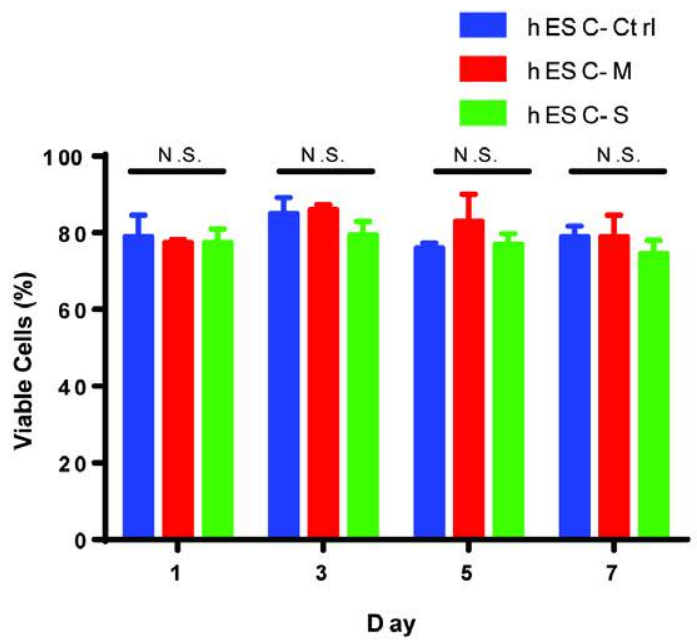

B

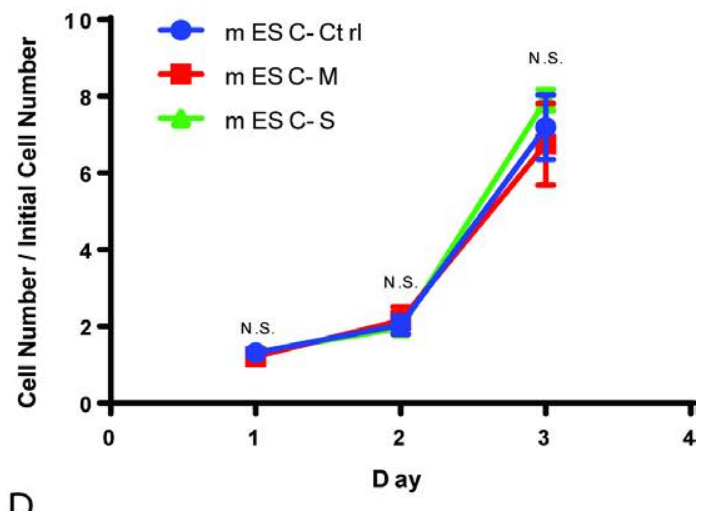

D

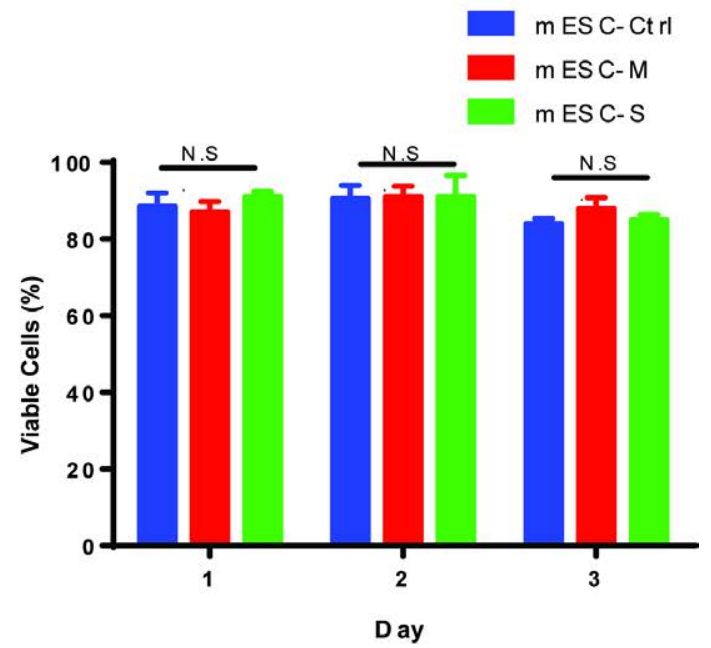

Figure 4: Cell growth kinetics and viability of transduced cell lines. (A) All transduced hESC lines showed similar cell growth rate regardless of the presence of either $\mathrm{H} 2-\mathrm{BI}$ molecule. (B) No significant difference was observed in the growth rate kinetics of any of the mESC lines. The percentage of viable cells detected in culture was not significantly altered in any of the hESC lines (C) or mESC lines (D) expressing either H2-BI isoform relative to controls.

of $\mathrm{M}-\mathrm{H} 2 \mathrm{Bl}$ or S-HSBl we next reselected all transduced mouse and human ES cell lines with a higher concentration of puromycin in order to re-establish lines with higher expression levels. However, following a second round of injections all of the $\mathrm{H} 2-\mathrm{Bl}$ transduced lines again failed to generate teratomas in $\mathrm{C} 57 \mathrm{BL} / 6$ mice, despite increased $\mathrm{M}-\mathrm{H} 2 \mathrm{Bl}$ or $\mathrm{S}-\mathrm{H} 2 \mathrm{Bl}$ expression, while producing multilineage teratomas in NOD/ SCID recipients.

\section{Discussion}

The generation of an ESC donor cell line capable of being accepted by all recipients would greatly improve the potential of hESC and iPSC based regenerative medicine and help to facilitate the testing of cellular products in small and large animal species. Our data show that expression of the soluble and membrane bound forms of $\mathrm{H} 2-\mathrm{Bl}$ does not interfere with proliferation, viability or differentiation capacity of mouse or human ES cells and inhibits CD8+ splenocyte proliferation responses in vivo. However, this by itself proved insufficient to permit xenogenic or allogenic teratoma formation in immune competent mice. As short term teratoma formation has been shown to be permitted in immunocompetent mice in situations of isogenic iPS transplantation
[16], as well as immune suppression [14], we believe this to be a valid assay for the characterization of potential immune suppression regimens.

Although we detected robust expression of both the soluble and membrane bound forms of $\mathrm{H} 2-\mathrm{Bl}$ in our ES cell lines, and tested clones with even higher expression, it is possible that expression levels were still not sufficient to overcome T-cell mediated lysis. We further note that in the NRG recipient mouse model used in our T-cell activation assay there was a relatively high background proliferation rate in CD8+ cells, likely due to the homeostatic proliferation which is known to occur in response to signals of lymphopenia in these recipient animals. As such, the observed inhibition of CD8+ division may not have been solely due to $\mathrm{T}$ cell activation associated with immune rejection. However, given previous publications involving the human HLA-G protein, our results are consistent with the inhibition of a cytotoxic $\mathrm{T}$ lymphocyte response [22].

An important immunological difference between NOD/SCID and C57BL/6 mice is the lack of detectable haemolytic complement in NOD/SCID mice [35]. Given that complement plays a major role in 
A

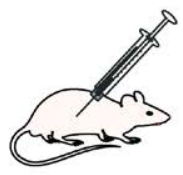

Day 0

hESC Injection

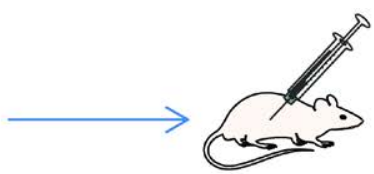

Day 1

VPD450 CD8+

Splenocyte Injection

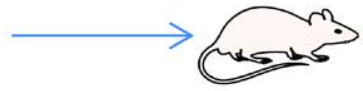

Day 7

FACS Analysis for CD8

Proliferation in Spleen
B

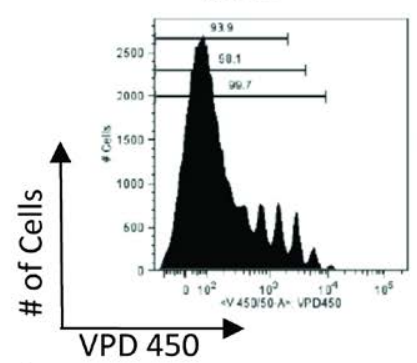

C

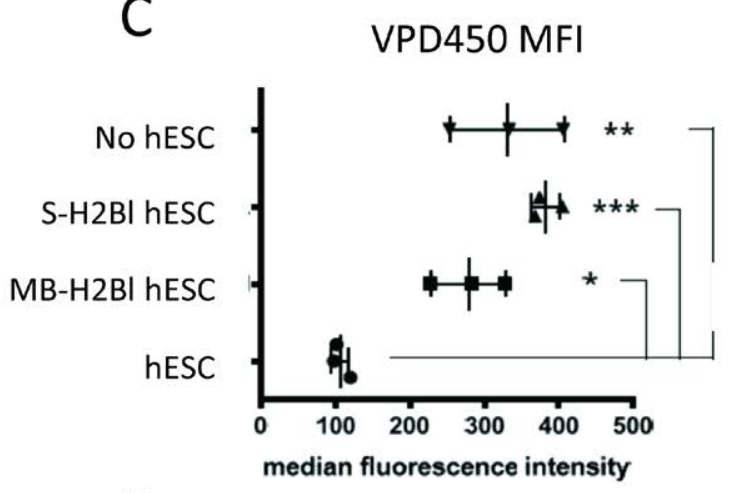

E

$\%$ CD8+Cells $\geq 2$ Division

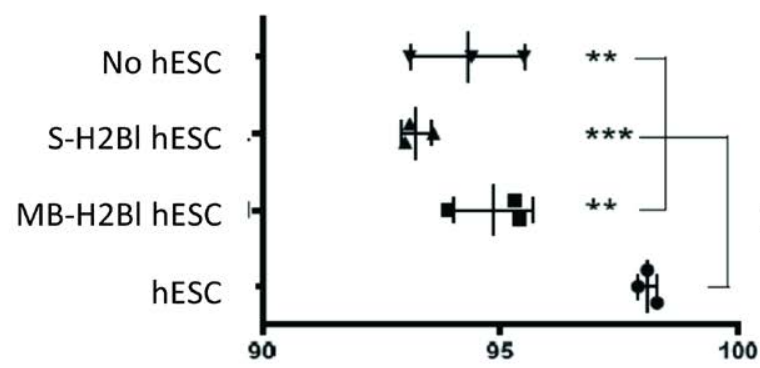

S-H2BI hESC

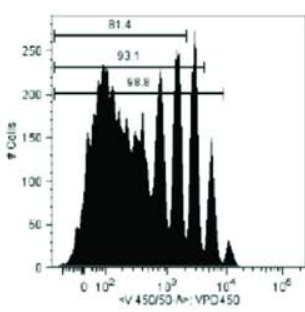

No hESC

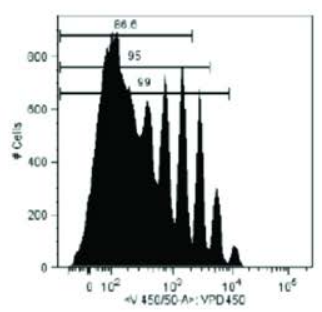

$\%$ CD8+Cells $\geq 1$ Division
D

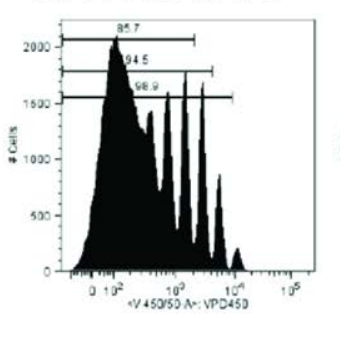

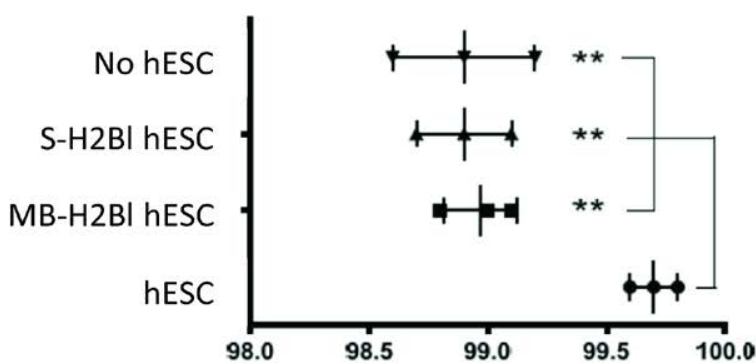

F

$\%$ CD8+ Cells $\geq 3$ Division

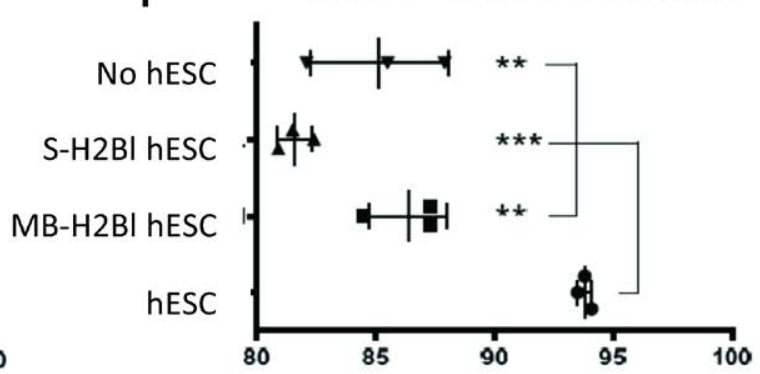

Figure 5: H2-BI S and MB inhibit CD8+ T cell proliferation. (A) Schematic representation of experiments. (B) Representative flow cytometry histograms of VPD450 in CD8+ cells from the spleen of recipients. (C) CD8+ splenocyets injected in recipients containing ES cells expressing either S-H2BI or MB-H2BI showed a decrease in the median florescence intensity of VPD. (D-F) CD8+ cell proliferation was significantly lower in when injected into mice containing ES cells expressing either S-H2B or MB-H2BI relative to control ES cells, and was similar to that seen in mice that had not received ES cell injections. $\left(n=3,{ }^{*} p<0.05,{ }^{* *} p<0.01,{ }^{\star * *} p<0.001\right)$.

early and hyper-acute graft rejection [36] and that there is no known role for HLA-G/H2-Bl with regards to inhibition of the complement pathway, it is possible that the rejection of our transplantations into immune competent C57BL/6 mice was facilitated via the complement pathway. As such, future attempts at utilizing $\mathrm{H} 2-\mathrm{Bl}$ may benefit from the addition of complement inhibitors such as sCR1, CR2-Crry, or CR2-fH during transplantation, as they have been shown to be useful in previous transplantation models $[37,38]$.
We conclude that similar to knock-down of HLA class I, expression of $\mathrm{H} 2-\mathrm{Bl}$ in ESCs is not sufficient to fully protect grafts from immune mediated rejection. It will be interesting to assess whether HLA-G/H2$\mathrm{Bl}$ expression can play a role in overcoming the immune rejection of iPSCs and whether the expression of $\mathrm{H} 2-\mathrm{Bl}$ in combination with the deletion of MHC can be effective. It is also worthwhile investigating whether concurrent inhibition of complement mediated immunity is also required. In our opinion the quest for such a universal donor line, 
Citation: Dingwall S, Brooks A, Apte SH, Waters M, Lavin MF, et al. (2015) Expression of Histocompatibility 2 Blastocyst (H2-BI) in Embryonic Stem Cells Inhibits CD8+ T-Cell Activation but is not Sufficient to Facilitate Graft Tolerance. J Stem Cell Res Ther 5: 320. doi:10.4172/21577633.1000320

Page 7 of 8

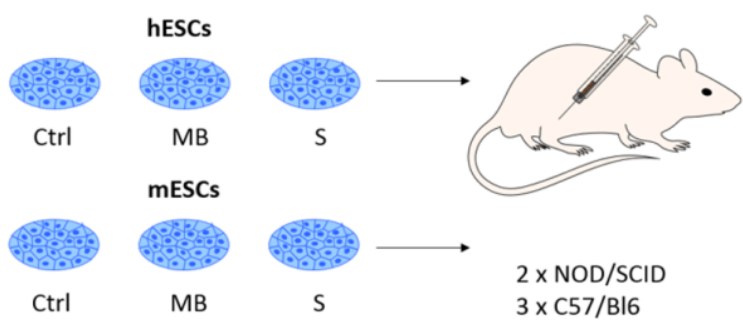

Injection Round 1

$\begin{array}{rcc} & N O D / S C I D & C 57 / B 16 \\ \text { hESC-Ctrl } & 1 / 2 & 0 / 3 \\ \text { hESC-MB } & 2 / 2 & 0 / 3 \\ \text { hESC-S } & 2 / 2 & 0 / 3 \\ \text { mESC-Ctrl } & 1 / 2 & 0 / 3 \\ \text { mESC-MB } & 1 / 2 & 0 / 3 \\ \text { mESC-S } & 2 / 2 & 0 / 3\end{array}$

Injection Round 2

NOD/SCID $\quad C 57 / B 16$

$2 / 2 \quad 0 / 3$

$2 / 2$

$0 / 3$

$1 / 2 \quad 0 / 3$

$2 / 2 \quad 0 / 3$

$1 / 2 \quad 0 / 3$

$2 / 2 \quad 0 / 3$

Figure 6: Teratoma formation in immune compromised and immune competent mice. Teratoma formation was observed in all non-obese diabetic/severe combined immunodeficiency (NOD/SCID) injected with ES cells upon intramuscular injection of $1 \times 10^{6} \mathrm{ES}$ cells. No teratoma formation was observed in any C57BL/6 mice.

although at present elusive, is a viable and worthwhile exercise in light of the enormous scientific and medical benefits that such a line would bring to regenerative medicine approaches.

\section{References}

1. Magliocca JF, Held IK, Odorico JS (2006) Undifferentiated murine embryonic stem cells cannot induce portal tolerance but may possess immune privilege secondary to reduced major histocompatibility complex antigen expression. Stem Cells Dev 15: 707-717. [PubMed]

2. Koch CA, Geraldes P, Platt JL (2008) Immunosuppression by embryonic stem cells. Stem Cells 26: 89-98. [PubMed]

3. Drukker M, Katz G, Urbach A, Schuldiner M, Markel G, et al. (2002) Characterization of the expression of MHC proteins in human embryonic stem cells. Proc Natl Acad Sci USA 99: 9864-9869. [PubMed]

4. Bradley JA, Bolton EM, Pedersen RA (2002) Stem cell medicine encounters the immune system. Nat Rev Immunol 2: 859-871. [PubMed]

5. Deuse T, Seifert M, Tyan D, Tsao PS, Hua X, et al. (2011) Immunobiology of naive and genetically modified HLA-class-I-knockdown human embryonic stem cells. J Cell Sci 124: 3029-3037. [PubMed]

6. Taylor CJ, Peacock S, Chaudhry AN, Bradley JA, Bolton EM (2012) Generating an iPSC bank for HLA-matched tissue transplantation based on known donor and recipient HLA types. Cell Stem Cell 11: 147-152. [PubMed]

7. Robertson NJ, Brook FA, Gardner RL, Cobbold SP, Waldmann H, et al. (2007) Embryonic stem cell-derived tissues are immunogenic but their inherent immune privilege promotes the induction of tolerance. Proc Natl Acad Sci USA 104: 20920-20925. [PubMed]

8. Swijnenburg RJ, Schrepfer S, Govaert JA, Cao F, Ransohoff K, et al. (2008) Immunosuppressive therapy mitigates immunological rejection of human embryonic stem cell xenografts. Proc Natl Acad Sci USA 105: 12991-12996. [PubMed]

9. Buhnemann C, Scholz A, Bernreuther C, Malik CY, Braun H, et al. (2006) Neuronal differentiation of transplanted embryonic stem cell-derived precursors in stroke lesions of adult rats. Brain 129: 3238-3248. [PubMed]

10. Caspi O, Huber I, Kehat I, Habib M, Arbel G, et al. (2007) Transplantation of human embryonic stem cell-derived cardiomyocytes improves myocardia performance in infarcted rat hearts. J Am Coll Cardiol 50: 1884-1893. [PubMed]

11. Lamba D, Karl M, Reh T (2008) Neural regeneration and cell replacement: a view from the eye. Cell Stem Cell 2: 538-549. [PubMed]
12. Lamba DA, Gust J, Reh TA (2009) Transplantation of human embryonic stem cell-derived photoreceptors restores some visual function in $\mathrm{Crx}$-deficient mice. Cell Stem Cell 4: 73-79. [PubMed]

13. Toriumi H, et al. (2009) Treatment of Parkinson's disease model mice with allogeneic embryonic stem cells: necessity of immunosuppressive treatment for sustained improvement. Neurol Res 31: 220-227. [PubMed]

14. Pearl JI, Lee AS, Leveson-Gower DB, Sun N, Ghosh Z, et al. (2011) Shortterm immunosuppression promotes engraftment of embryonic and induced pluripotent stem cells. Cell Stem Cell 8: 309-317. [PubMed]

15. Zhao T, Zhang ZN, Rong Z, Xu Y (2011) Immunogenicity of induced pluripotent stem cells. Nature 474: 212-215. [PubMed]

16. Guha P, Morgan JW, Mostoslavsky G, Rodrigues NP, Boyd AS (2013) Lack of Immune Response to Differentiated Cells Derived from Syngeneic Induced Pluripotent Stem Cells. Cell Stem Cell 12: 407-412. [PubMed]

17. Zhao T, Zhang ZN, Westenskow PD, Todorova D, Hu Z, et al. (2015) Humanized Mice Reveal Differential Immunogenicity of Cells Derived from Autologous Induced Pluripotent Stem Cells. Cell Stem Cell 17: 353-359. [PubMed]

18. Kovats S, Main EK, Librach C, Stubblebine M, Fisher SJ, et al. (1990) A class I antigen, HLA-G, expressed in human trophoblasts. Science 248: 220-223. [PubMed]

19. Rouas-Freiss N, Gonçalves RM, Menier C, Dausset J, Carosella ED, et al (1997) Direct evidence to support the role of HLA-G in protecting the fetus from maternal uterine natural killer cytolysis. Proc Natl Acad Sci USA 94: 11520 11525. [PubMed]

20. Rouas-Freiss N, Marchal RE, Kirszenbaum M, Dausset J, Carosella ED (1997) The alpha1 domain of HLA-G1 and HLA-G2 inhibits cytotoxicity induced by natural killer cells: is HLA-G the public ligand for natural killer cell inhibitory receptors? Proc Natl Acad Sci USA 94: 5249-5254. [PubMed]

21. Walsh PT, Strom TB, Turka LA (2004) Routes to transplant tolerance versus rejection; the role of cytokines. Immunity 20: 121-131. [PubMed]

22. Le Gal FA, Riteau B, Sedlik C, Khalil-Daher I, Menier C, et al. (1999) HLA-Gmediated inhibition of antigen-specific cytotoxic $\mathrm{T}$ lymphocytes. Int Immunol. 11: 1351-1356. [PubMed]

23. Riteau B, Menier C, Khalil-Daher I, Sedlik C, Dausset J, et al. (1999) HLA-G inhibits the allogeneic proliferative response. J Reprod Immunol 43: 203-211. [PubMed]

24. LeMaoult J, Krawice-Radanne I, Dausset J, Carosella ED (2004) HLA-G1- 
Citation: Dingwall S, Brooks A, Apte SH, Waters M, Lavin MF, et al. (2015) Expression of Histocompatibility 2 Blastocyst (H2-BI) in Embryonic Stem Cells Inhibits CD8+ T-Cell Activation but is not Sufficient to Facilitate Graft Tolerance. J Stem Cell Res Ther 5: 320. doi:10.4172/21577633.1000320

Page 8 of 8

expressing antigen-presenting cells induce immunosuppressive CD4+ T cells. Proc Natl Acad Sci USA 101: 7064-7069. [PubMed]

25. Ristich V, Liang S, Zhang W, Wu J, Horuzsko A (2005) Tolerization of dendritic cells by HLA-G. Eur J Immunol. 35: 1133-1142. [PubMed]

26. Lila N, Amrein C, Guillemain R, Chevalier P, Latremouille C, et al. (2002) Human leukocyte antigen-G expression after heart transplantation is associated with a reduced incidence of rejection. Circulation 105: 1949-1954. [PubMed]

27. Zarkhin V, Talisetti A, Li L, Wozniak LJ, McDiarmid SV, et al. (2010) Expression of soluble HLA-G identifies favorable outcomes in liver transplant recipients. Transplantation 90: 1000-1005. [PubMed]

28. Creput C, Durrbach A, Menier C, Guettier C, Samuel D, et al. (2003) Human leukocyte antigen-G (HLA-G) expression in biliary epithelial cells is associated with allograft acceptance in liver-kidney transplantation. J Hepatol 39: 587-594. [PubMed]

29. Wiendl H, Mitsdoerffer M, Hofmeister V, Wischhusen J, Weiss EH, et al. (2003) The non-classical MHC molecule HLA-G protects human muscle cells from immune-mediated lysis: implications for myoblast transplantation and gene therapy. Brain 126: 176-185. [PubMed]

30. Gonzalez A, Rebmann V, LeMaoult J, Horn PA, Carosella ED, et al. (2012) The immunosuppressive molecule HLA-G and its clinical implications. Crit Rev Clin Lab Sci 49: 63-84. [PubMed]

31. Guidry PA, Stroynowski I (2005) The murine family of gut-restricted class lb
MHC includes alternatively spliced isoforms of the proposed HLA-G homolog, "blastocyst MHC". J Immunol 175: 5248-5259. [PubMed]

32. Amiot L, Vu N, Samson M (2015) Biology of the immunomodulatory molecule HLA-G in human liver diseases. J Hepatol 62: 1430-1437. [PubMed]

33. Costa M, Dottori M, Ng E, Hawes SM, Sourris K, et al. (2005) The hESC line Envy expresses high levels of GFP in all differentiated progeny. Nat Methods 2: 259-260. [PubMed]

34. Swijnenburg RJ, Schrepfer S, Cao F, Pearl JI, Xie X, et al. (2008) In vivo imaging of embryonic stem cells reveals patterns of survival and immune rejection following transplantation. Stem Cells Dev 17: 1023-1029. [PubMed]

35. Shultz LD, Schweitzer PA, Christianson SW, Gott B, Schweitzer IB, et al. (1995) Multiple defects in innate and adaptive immunologic function in NOD/ LtSz-scid mice. J Immunol 154: 180-191. [PubMed]

36. Lee JC, Christie JD (2009) Primary graft dysfunction. Proc Am Thorac Soc 6 39-46. [PubMed]

37. Atkinson C, He S, Morris K, Qiao F, Casey S, et al. (2010) Targeted complement inhibitors protect against posttransplant cardiac ischemia and reperfusion injury and reveal an important role for the alternative pathway of complement activation. J Immunol 185: 7007-7013. [PubMed]

38. Pruitt S, Bollinger RR, Collins BH, Marsh HC, Levin JL, et al. (1996) Continuous complement $(C)$ inhibition using soluble $C$ receptor type 1 (sCR1): effect on hyperacute rejection (HAR) of pig-to-primate cardiac xenografts. Transplant Proc 28: 756. [PubMed] 